\title{
Effect of Rubber Aggregates on the Thermophysical Properties of Self-Consolidating Concrete
}

\author{
Malek Jedidi $^{a} *$, Ahmed Gargouri ${ }^{\text {a,b }}$, Atef Daoud ${ }^{\text {b,c }}$ \\ ${ }^{a}$ Department of Civil Engineering, Higher Institute of Technological Studies, B.P.88, 3099 Sfax, Tunisia \\ ${ }^{b}$ University of Tunis El Manar, National Engineering School of Tunis, Civil Engineering Laboratory, Tunis, Tunisia \\ ${ }^{c}$ University of Gabes, National Engineering School of Gabes, 6029 Tunisia
}

\begin{abstract}
In this work, our choice fell on the exploitation of rubber aggregates from used tires. In this context, an experimental study was conducted to provide more data on the effect of rubber aggregates on the thermophysical properties of selfconsolidating concrete (SCC). To this end, four sets of rectangular specimens were prepared by varying the proportion of the rubber aggregates with percentages of $0 \%, 10 \%, 20 \%$ and $30 \%$ of the volume of gravel .Tests on hardened self-consolidating concrete rubber SCCR included measuring the thermal conductivity and the thermal diffusivity by the method of the boxes at steady and determining the specific heat . The results showed that the thermal conductivity and thermal diffusivity were decreased according to the increase of the percentage of rubber aggregates. This decrease was significantly improved thermal performance of the SCCR.
\end{abstract}

Keywords: Rubber aggregates, Self-consolidating concrete, Thermal conductivity, Thermal diffusivity, Specific heat.

\section{Introduction}

Increasing energy prices and depletion of natural resources are becoming pressing realities that need novel solutions [1]. Each year more than three million tires are discarded reaching the end of life. This is a cumbersome waste and environmental pollution ecology destabilizes [2]. The use of waste in construction materials can meet the need of conservation of natural aggregate resources (especially that the country can pose a significant lack in aggregate) and can also protect the environment by reducing landfill only to final waste $[3,4]$. Technological development in the manufacture of concrete through the creation of new additives allowed to make concrete more sophisticated including self-consolidating concrete (SCC). This material is characterized by its fluidity, ease of implementation and ability to fill formwork heavily armed. The possibility of designing a self-compacting concrete with rubber aggregates (SCCR) seems particularly interesting insofar as this material combines the properties of a SCC and of a material from the recycling of industrial waste which gives a cheapest composite [5]. The research into the SCCR remains limited because the addition of rubber aggregate in the concrete mixtures exhibits a loss in strength [6].

${ }^{*}$ Corresponding author. Tel.: +21698258681

Fax: +21698258681; E-mail: malekjedidi@yahoo.fr

(C) 2014 International Association for Sharing Knowledge and Sustainability

DOI: $10.5383 /$ ijtee.08.01.001
Several recent studies explore the increase in compatibility of crumb rubber aggregates when used as a replacement in SCC mixes. For example, Ei-dieb et al. [7] reported that by adding less than $10 \%$ rubber through the replacement of coarse aggregate does not significantly hinder the performance of the concrete, reducing strength by around 10-15\%. Eldin and Senouci [6] found that SCRR exhibits a ductile and plastic failure. Therefore, it has the ability to absorb a large amount of plastic energy under compressive and tensile loads. El-Gammal et al. [8] reported that, in general, the SCCR have acceptable workability in terms of ease of handling, placement, and finishing. The research conducted by Zheng [9] reported that Recent the addition of rubber can increase the vibration absorption of a concrete slab. There is a wide-range of possible civil engineering applications for SCCR. Examples include architectural applications such pavements, floors, walls, false facades and stone backing [10]. It can still be used for the construction of footpath, driveways and selected road construction applications due to its high toughness qualities $[6,11,12]$. Therefore, SCCR can be used for applications requiring deformable concrete with high flowability and low/medium strength $(<35 \mathrm{MPa})$, which is difficult to achieve using SCC [13,14]. El-Gammal et al. [8] reported that RMSCC can also be used in the production of road kerbs, and nonbearing concrete walls. 
In order to understand the fundamental properties of SCCR and how it performs in its intended application, a study was undertaken to carefully monitor the production of SCCR, investigating the effect of adding rubber aggregates in SCC on the fundamental thermophysical properties such as thermal conductivity, thermal diffusivity and the specific heat using local materials and incorporating rubber aggregates with percentages of $0 \%, 10 \%, 20 \%$ and $30 \%$ of the volume of gravel.

\section{Experimental study}

\subsection{Materials characteristics}

The cement used was a CEM I 32.5 in conformity with Tunisian Standard NT 47.01produced by the Cement Company of GABES. It has an absolute density of $3.10 \mathrm{~g} / \mathrm{cm} 3$ and a Blaine specific surface of $380 \mathrm{~m}^{2} / \mathrm{Kg}$. The physical characteristics of the aggregates used in the preparation of concrete specimens are shown in Table 1.

Table 1. Physical characteristics of the aggregates

\begin{tabular}{ccccc}
\multicolumn{4}{c}{ Table 1. Physical characteristics of the aggregates } \\
\hline $\begin{array}{c}\text { Los } \\
\text { Angeles } \\
(\%)\end{array}$ & $\begin{array}{c}\text { Fineness } \\
\text { modulus }\end{array}$ & $\begin{array}{c}\text { Absorption } \\
(\%)\end{array}$ & $\begin{array}{c}\text { Specific } \\
\text { gravity } \\
\left(\mathrm{g} / \mathrm{cm}^{3}\right)\end{array}$ \\
\hline Sand 0/4 & - & 2.51 & 3.20 & 2.61 \\
Gravel 4/8 & 34 & - & 2.50 & 2.73 \\
Gravel 8/16 & 35 & - & 2.40 & 2.76 \\
\hline
\end{tabular}

The rubber aggregates are obtained by grinding used of-life tires following two particle-size cuts $0 / 4$ and $4 / 8$ (Fig. 1). The actual density of rubber aggregates is equal to $0.95 \mathrm{~g} / \mathrm{cm}^{3}$.
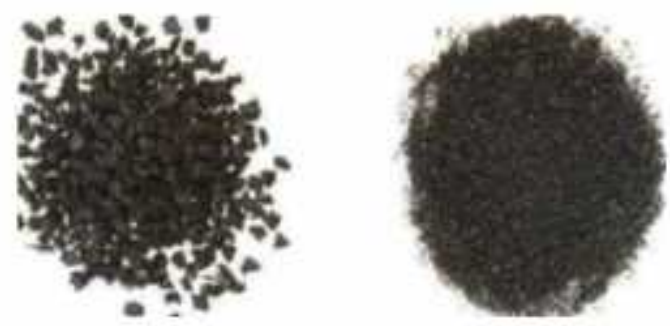

Fig. 1. The rubber aggregates
The employed admixture was a superplasticizer (SP) used to increase markedly the workability of concrete according to the requirements of NF EN 934-2+A1 [15]. The dosage was $1 \%$ by weight of cement. The physicochemical characteristics of the used SP are given in Table 2.

Table 2. Physicochemical characteristics of the SP

\begin{tabular}{|c|c|c|c|c|}
\hline Density & $\mathrm{pH}$ & $\begin{array}{c}\mathrm{Na}_{2} \mathrm{OEq} \\
(\text { (ow) }\end{array}$ & $\begin{array}{c}\text { Dry extract } \\
\text { (ol) }\end{array}$ & $\mathrm{CI}^{-}$ \\
\hline $1.06 \pm 0.01$ & 4.5 à 6.5 & $\leq 1 \%$ & 28.0 à 31.0 & $\leq 0.1 \%$ \\
\hline
\end{tabular}

\subsection{Mixtures}

Four sets of Parallelepiped specimens (270 mm x $270 \mathrm{~mm}$ x 40 $\mathrm{mm}$ ) were prepared by varying the proportion of the rubber aggregates with percentages of $0 \%, 10 \%, 20 \%$ and $30 \%$ of the volume of gravel (Fig . 2).

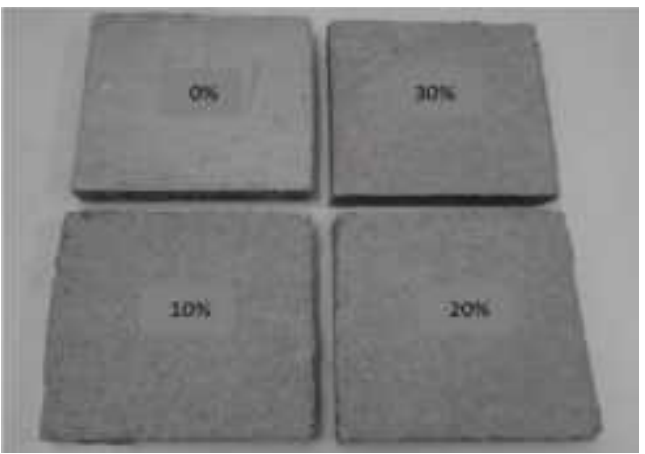

Fig. 2. Parallelepiped Specimens tested

The values $(0,10,20$, and 30$)$ indicate the proportion of the rubber aggregates by substitution of the volume of gravel. The Self-Consolidating Concrete and the Self-Consolidating Concrete with Rubber aggregates were respectively designated as SCC and SCCR.

In order to obtain a self compactability of concrete with high deformability and resistance to segregation, the following methods were used [16]:
a. Limited aggregate content
b. Low powder-water ratio
c. Use of superplasticizer

The method of achieving self compactability of concrete is shown in Fig.3.

Table 3. Composition of the SCC and SCCR specimens

\begin{tabular}{|c|c|c|c|c|c|c|c|c|c|c|c|}
\hline \multirow{2}{*}{ Mixtures } & \multirow{2}{*}{$\mathrm{W} / \mathrm{C}$} & \multicolumn{3}{|c|}{ Rubber $[\mathrm{Kg}]$} & \multirow{2}{*}{$\begin{array}{c}\text { Cement } \\
{[\mathrm{Kg}]}\end{array}$} & \multirow{2}{*}{$\begin{array}{l}\text { Water } \\
{[\mathrm{Kg}]}\end{array}$} & \multicolumn{2}{|c|}{ Gravel $[\mathrm{Kg}]$} & \multirow{2}{*}{$\begin{array}{l}\text { Sand } \\
{[\mathrm{Kg}]}\end{array}$} & \multirow{2}{*}{$\begin{array}{c}\text { Filers } \\
{[\mathrm{Kg}]}\end{array}$} & \multirow{2}{*}{$\begin{array}{c}\mathrm{SP} \\
{[\mathrm{Kg}]}\end{array}$} \\
\hline & & $\%$ & $0 / 4$ & $4 / 8$ & & & $4 / 8$ & $8 / 16$ & & & \\
\hline SCCOR & 0.55 & 0 & 0 & 0 & 350 & 195 & 540 & 360 & 900 & 100 & 7.7 \\
\hline SCC10R & 0.55 & 10 & 41.4 & 23.6 & 350 & 195 & 486 & 360 & 810 & 100 & 7.7 \\
\hline SCC20R & 0.55 & 20 & 82.3 & 47.4 & 350 & 195 & 432 & 360 & 720 & 100 & 8.8 \\
\hline SCC30R & 0.55 & 30 & 70.8 & 123.6 & 350 & 195 & 258 & 360 & 746 & 100 & 9.5 \\
\hline
\end{tabular}




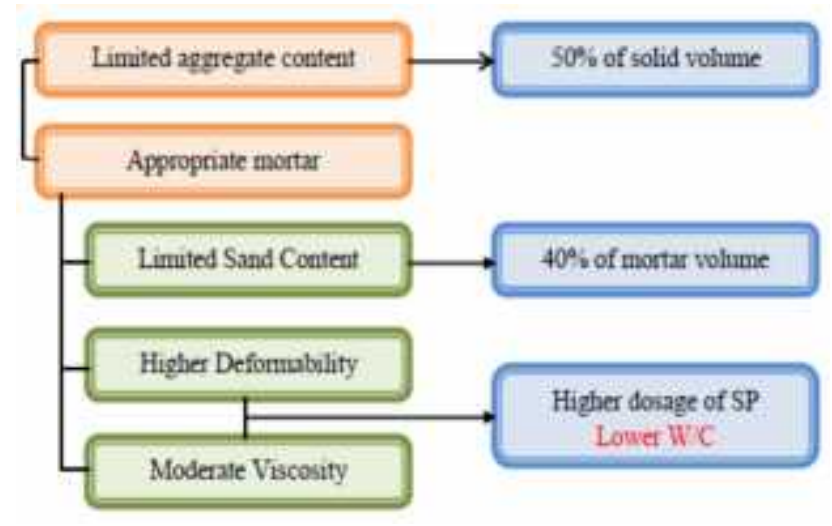

Fig. 3. Methods of achieving self compactability

The composition of all prepared mixtures is given in Table 3 . Effective water/cement ratio was 0.55 and kept constant in all mixtures. The parallelepiped specimens were used to determine the thermal conductivity and the thermal diffusivity of the different mixtures at the age of 28 days by the boxes method.
Specific heat was predicted from the thermal conductivity and the thermal diffusivity data.

Test specimens were kept in their molds. After $24 \mathrm{~h}$, they were removed from the mold and subjected to water curing at $20^{\circ} \mathrm{C}$. At the correspondent age, the specimens were taken out and kept in laboratory conditions until testing time.

\section{Test procedures}

\subsection{Workability of fresh mixtures}

In this study, the recommended European Guidelines for SelfCompacting Concrete were adopted to assess flow ability (Slump flow test), Viscosity by measuring the emptying time measuring the concentrated suspension (V-funnel test) and passing ability (L-box) test for fresh SCC and SCCR mixtures. The specifications for the slump flow test, V-funnel test and Lbox test are also taken from EFNARC [17]. The equipment is shown in Fig. 4.
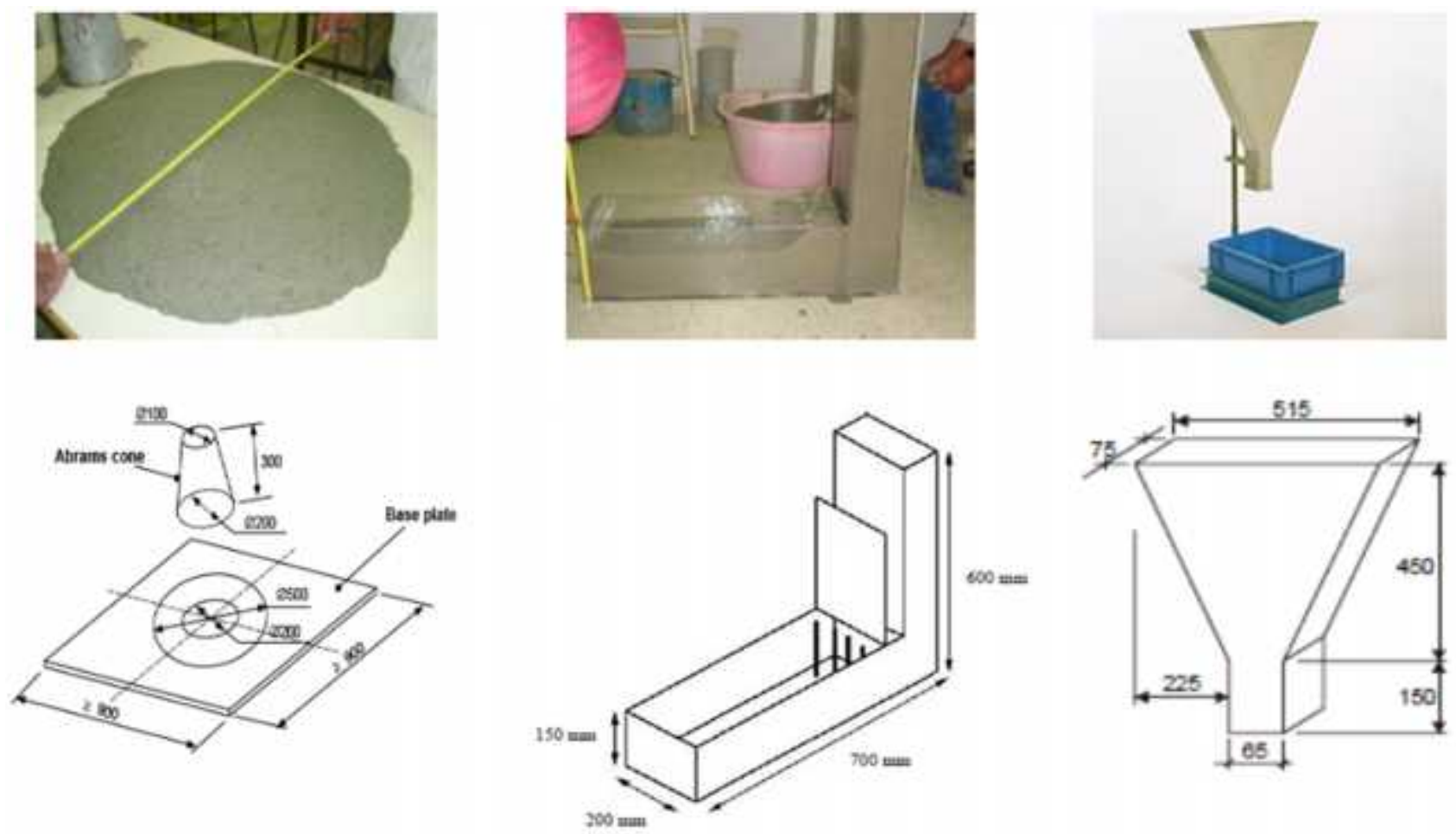

Fig. 4. Slump flow, L-box and V-funnel

\subsection{Thermophysical properties of mixtures}

\subsubsection{Thermal conductivity measurement}

The thermal conductivity for the mixtures was determined using parallelepiped specimens in accordance with the requirements of NF EN ISO 8990 [18]. The method used is the boxes method [19-20]. This is a device used in the laboratory of building physics that is capable to measuring thermal conductivity and thermal diffusivity of a material (Fig.5). The system consists of:
- Boxes B1 and B2: manufactured against plated. They are isolated by the highly styrodure to prevent heat losses to the outside. A heating resistor $(\mathrm{R})$ is placed inside the box B1to act as hot atmosphere.

- Enclosure: highly insulated chamber which acts as a cold atmosphere maintained at a temperature of $\theta=4{ }^{\circ} \mathrm{C}$ by a cooling system.

- Measuring strip: This is displayed on the different values of the temperatures sensed by temperature sensors platinum. 
The principle of measurement of the thermal conductivity is based on the realization of a unidirectional heat flow through the test sample and records the values of different temperatures.

Knowing that:

$$
\phi_{e}=\phi_{T}+\phi_{P}
$$

where:

The flux emitted by the heating element is:

$$
\begin{gathered}
\phi_{e}=\frac{U^{2}}{R} \\
\phi_{P}=C \cdot\left(T_{B}-T_{a}\right)
\end{gathered}
$$

The flux transmitted by conduction through the sample is :

$$
\phi_{T}=\frac{\lambda_{\text {exp }}}{e} \cdot S \cdot\left(T_{1}-T_{2}\right)
$$

If we replace flows by their values, the following expression is obtained

$$
\frac{U^{2}}{R}=\frac{\lambda_{\exp }}{e} . S .\left(T_{1}-T_{2}\right)+C .\left(T_{B}-T_{a}\right)
$$

According to equation (5), we can deduce the expression of the thermal conductivity $\lambda_{\exp }$ determined by the box method:

$$
\lambda_{\text {exp }}=\frac{e}{S .\left(T_{1}-T_{2}\right)}\left[\frac{U^{2}}{R}-C .\left(T_{B}-T_{a}\right)\right]
$$

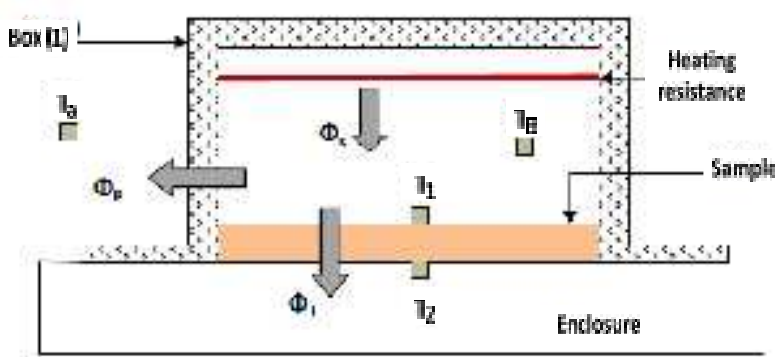

Fig. 5. Thermal conductivity testing apparatus

\subsubsection{Thermal diffusivity measurement}

The thermal diffusivity measurements apparatus used in this study is the same as that for thermal conductivity measurement. In addition, the box (2) is fitted with an incandescent lamp of $1000 \mathrm{~W}$ at its superior face instead of the heating resistance (Fig. 6). The internal faces of the box are reflective in order to homogenize the flow on the irradiated face of sample.

The principle of the experimental measurement method is to emit a heat flux, for a few seconds by means of the lamp, on one face of the sample and then the thermal diffusivity is evaluated from the temperature variation of the non irradiated face of sample [21]. Using Degiovanni model based on the method of part-time [22], the thermal diffusivity is given as follows:

$$
\alpha=\frac{\alpha_{1 / 2}+\alpha_{2 / 3}+\alpha_{1 / 3}}{3}
$$

Where :

$\alpha_{1 / 2}=e^{2}\left[\frac{0.761 t_{5 / 6}-0.926 t_{1 / 2}}{\left(t_{5 / 6}\right)^{2}}\right]$

$\alpha_{2 / 3}=e^{2}\left[\frac{1.150 t_{5 / 6}-1.250 t_{2 / 3}}{\left(t_{5 / 6}\right)^{2}}\right]$

$\alpha_{1 / 3}=e^{2}\left[\frac{0.617 t_{5 / 6}-0.862 t_{1 / 3}}{\left(t_{5 / 6}\right)^{2}}\right]$

[ $t_{i j j}:$ the time corresponds to the ratio $i / j$ of the maximum temperature (s)]

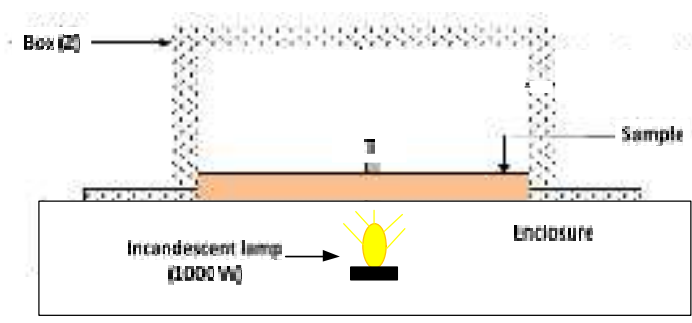

Fig. 6. Thermal diffusivity testing apparatus

\subsubsection{Specific heat}

The specific heat $\left(\mathrm{C}_{\mathrm{p}}\right)$ represents the heat amount required to raise the temperature by one degree of a mass unity of a material. More heat energy is required to increase the temperature of a substance with high specific heat capacity than when using low specific heat capacity material. Dividing heat capacity by the body's mass yields a specific heat capacity, which is no longer dependent on the amount of material but on the type of material and on the temperature.

The specific heat is determined from measurements of the thermal conductivity and diffusivity by using the following relation: [23]

$$
C_{P}=\frac{\lambda_{\exp }}{\rho \cdot \alpha_{\exp }}
$$

\section{Experimental result and discussion}

\subsection{Slump flow test}

The slump flow test aims at investigating the filling ability of SCC. It measures two parameters: flow spread and flow time T50 (optional). The former indicates the free, unrestricted deformability and the latter indicates the rate of deformation within a defined flow distance. According to EFNARC [17], the typical slump value of the SCC mixtures should be between $650 \mathrm{~mm}$ to $800 \mathrm{~mm}$. 
Figure 7 show that the slump value for SCCOR is in conformity with the recommended guidelines. Instead, the slump values for mixtures with rubber aggregates are lower than the recommended guidelines. However, the incorporation of rubber aggregates considerably reduced the slump value of SCCR which tends to lose its workability far quicker than conventional SCC.

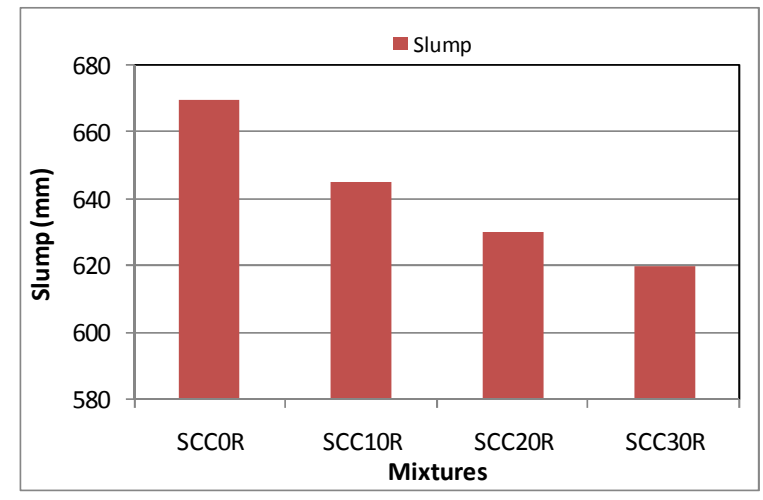

Fig. 7. Slump flow test

\subsection{L-box (passing ability)}

The method aims at investigating the passing ability of SCC. It measures the reached height of fresh SCC after passing through the specified gaps of steel bars and flowing within a defined flow distance. With this reached height, the passing or blocking behavior of SCC can be estimated.

Fig. 8 showed the passing ability ratio from the 3 bar L-box test. The results indicate that SCCR has a much lower passing ability ratio (0.52-0.62) when compared to SCC (0.84). However, the incorporation of rubber aggregates seems to have a negative effect on the passing ability of SCCR. Indeed, as the mix travelled through the L-box, the rubber particle seemed to create a blocking effect at the top of the opening which gradually increased until the stoppage of flow.

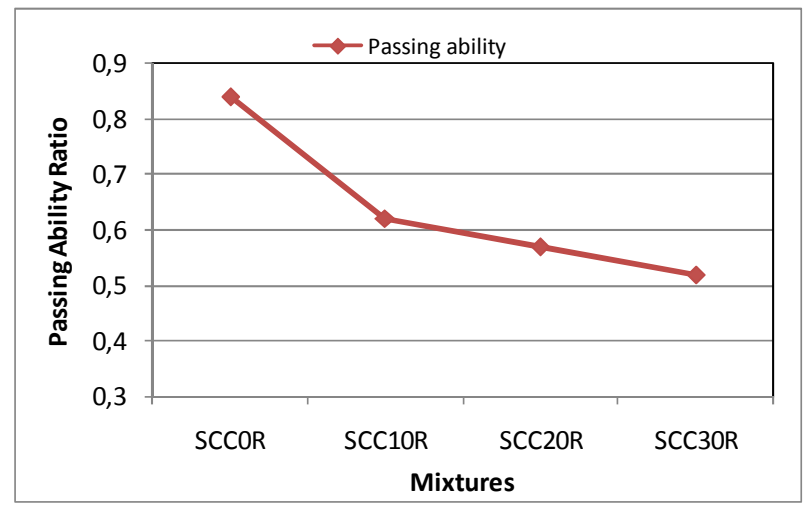

Fig. 8. L-box test (Passing Ability)

\subsection{V-funnel test}

The filling ability of the mixtures was evaluated through the $\mathrm{V}$ shaped funnel test. The flow time was determined using a simple procedure: the funnel is completely filled with fresh concrete, and the flow time is that between opening the orifice and the complete emptying of the funnel. According to EFNARC [17], a funnel test flow time less than 10 seconds is recommended for a concrete to qualify for a SCC.
The V-funnel test results are shown in Fig. 9. It is apparent that SCCR has a high viscosity and low filling ability compared to SCC. It is clear that the incorporation of rubber aggregates seems to increase the flow time of fresh concrete. Therefore, once the gate was opened, the flow increase was gradual and was further affected by the friction caused by rubber aggregates rubbing against the funnel walls.

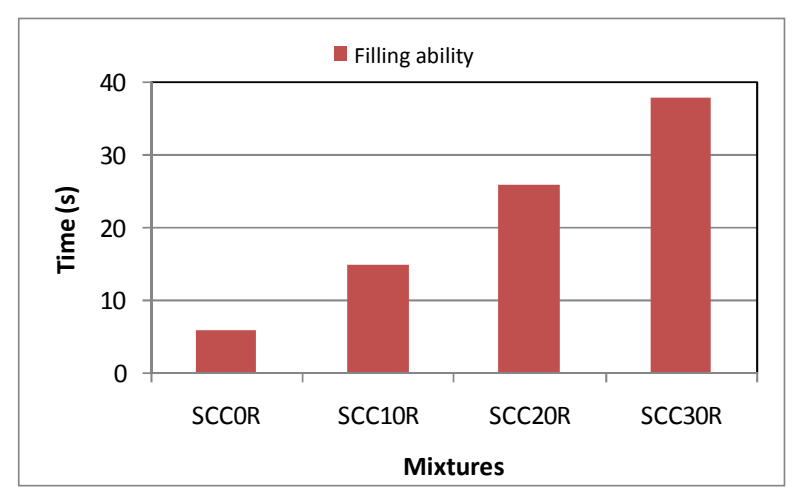

Fig. 9. Filling ability for the mixtures

\subsection{Density of SCCR}

Figure 10 shows the variation in dry density of the mixtures according to the content of the rubber aggregates. We note that the density decreases from $2150 \mathrm{~kg} / \mathrm{m} 3$ to $1702 \mathrm{~kg} / \mathrm{m}^{3}$ for content rubber aggregates ranging from $0 \%$ to $30 \%$ which corresponds to a reduction of about $21 \%$, particularly useful in rehabilitation and relief structures. This is due to the low specific gravity of the rubber $\left(0.95 \mathrm{Kg} / \mathrm{m}^{3}\right)$ compared to granulate $\left(2.70 \mathrm{Kg} / \mathrm{m}^{3}\right)$ and to the increasing air entrainment in the matrix due to the nature non-polar of rubber [24].

Test results also revealed that the density of SCCR ranges from medium weight to normal weight depending on the percentage of rubber aggregates replacement.

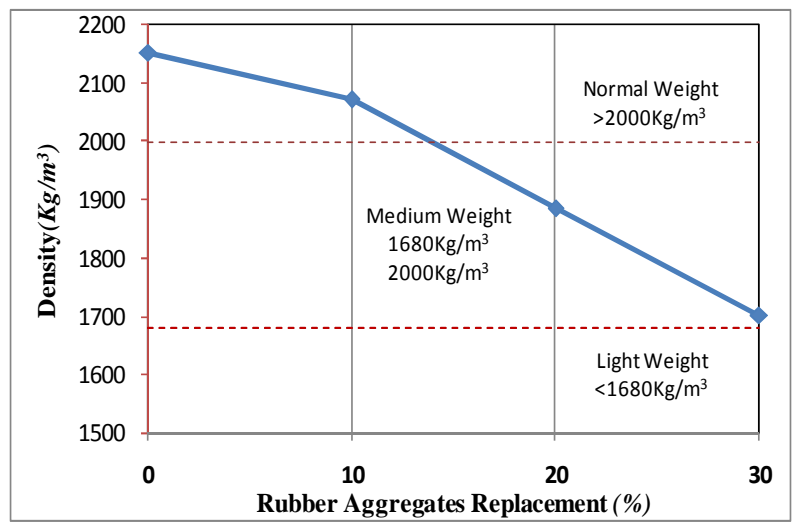

Fig. 10. Effect of rubber aggregates on the dry density

\subsection{Thermal conductivity}

The results given in Figure 11 show that the addition of rubber aggregates considerably reduce the thermal conductivity of different mixtures of $1.3 \mathrm{~W} / \mathrm{m} . \mathrm{K}$ to $0.76 \mathrm{~W} / \mathrm{m} . \mathrm{K}$. This decrease can be explained by the microstructure of mixtures. Indeed, air is trapped on the surface of rubber aggregates leading to an increase in the amount of air content. 
Since the thermal conductivity of the air $(0.025 \mathrm{~W} / \mathrm{m} . \mathrm{K})$ is less than of the concrete $(1.75 \mathrm{~W} / \mathrm{m} . \mathrm{K})$, the air voids opposes the thermal transfer through the mixtures. In addition, rubber aggregates also restrain thermal flow because the thermal conductivity of the rubber aggregates $(0.16 \mathrm{~W} / \mathrm{m} . \mathrm{K})$ is less than that of aggregate $(1.5 \mathrm{~W} / \mathrm{m} . \mathrm{K})$

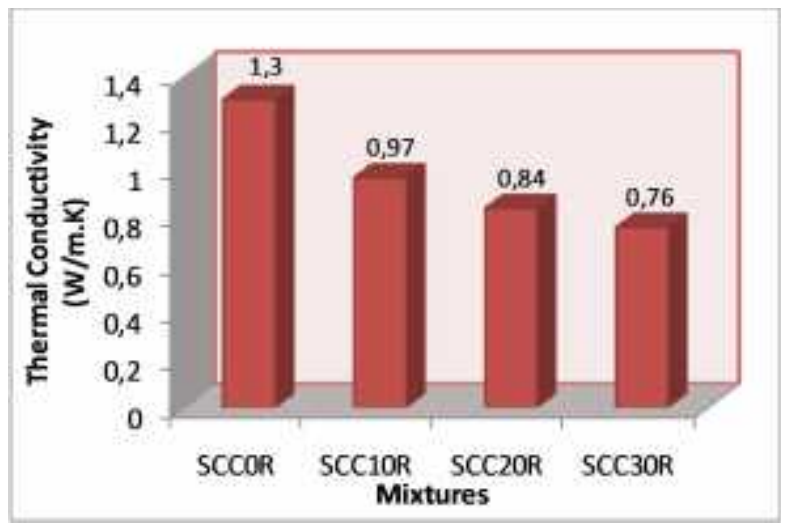

Fig. 11. Effect of rubber aggregates on the thermal conductivity

\subsection{Thermal diffusivity}

Thermal diffusivity was determined experimentally on specimens having a parallelepiped shape with the box method. Figure 12 presents the results of the thermal diffusivity measurements. According to the results, we note that the incorporation of rubber aggregates considerably reduced the thermal diffusivity and hence improved the thermal insulation of different mixtures. For example, the SCC10R and SCC20R produced respectively a $32.95 \%$ and $42.28 \%$ reduction in thermal diffusivity.

According to Fig. 11 and Fig 12, we note that a reduction of the thermal conductivity reduced the thermal diffusivity; this may be offset by the reduction in density necessary to achieve the lower thermal conductivity. For example, the SCC20R produced $35.38 \%$ reduction in thermal conductivity and also produced $42.28 \%$ reduction in thermal diffusivity.

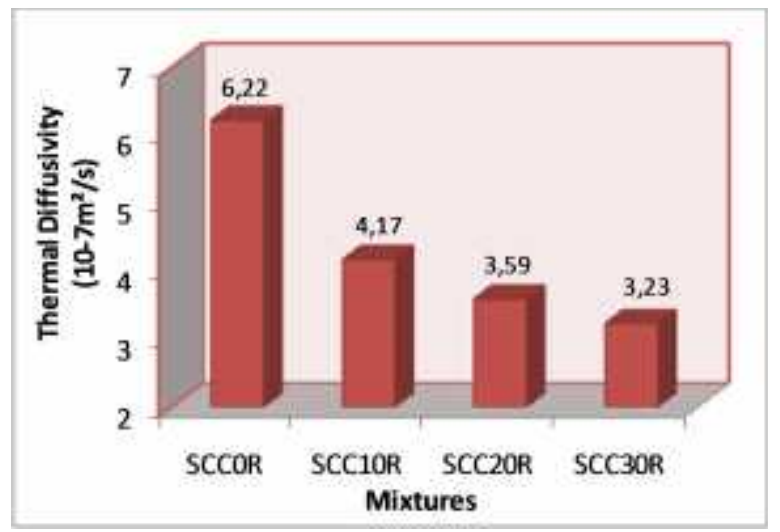

Fig. 12. Effect of rubber aggregates on the thermal diffusivity

\subsection{Specific heat}

The specific heat of the specimens was determined by calculation using Eq. 11 that combines thermal conductivity, density and thermal diffusivity into one value conform to the requirements of NF EN ISO 7345.

According to the results shown in Fig.13, the specific heat of specimens was increased with increasing rubber aggregates replacement and can reach a value of $1380 \mathrm{~J} / \mathrm{Kg} . \mathrm{K}$ for a percentage of $30 \%$. We note that thermal conductivity and specific heat varied in the opposite direction. For example, SCC30R produced $41.53 \%$ reduction in thermal conductivity and also produced $30 \%$ increasing in specific heat.

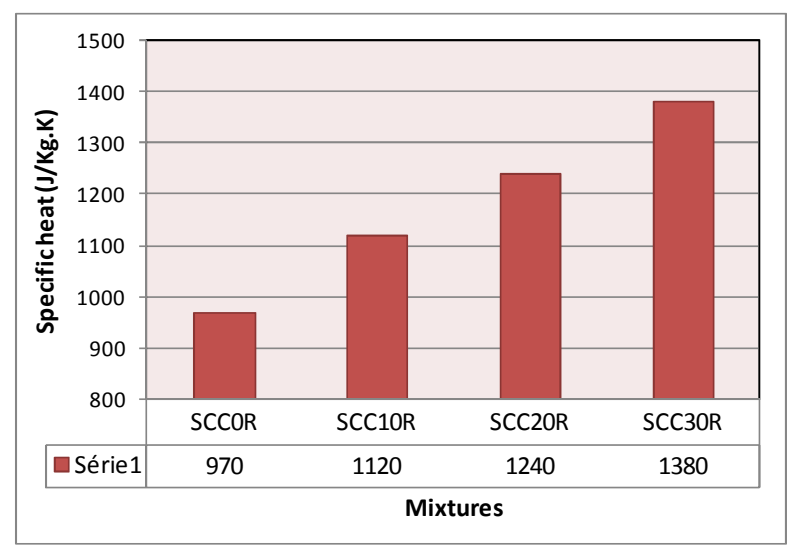

Fig. 13. Effect of rubber aggregates on the specific heat

\section{Conclusion}

The work presented concerning the effect of rubber aggregates on the thermophysical properties of SCC.

The results showed that SCCR had a lower flow rate compared to SCC. This is likely to be the effect of low density and smaller rubber aggregates resisting the flow. In addition to that, compared to SCC, SCCR had a high viscosity and low filling ability.

An examination of the physico-mechanical behavior showed a reduction of the mixture up to $22 \%$ for a volume rubber content of $30 \%$, which classifies the SCCR in the medium category.

The results also showed that the incorporation of rubber granulates allow reducing significantly the thermal conductivity of the mixtures. Furthermore, measurements of thermal diffusivity were highlighted SCCR capacity to transmit heat by conduction.

Furthermore, the addition of the rubber aggregates decreased the speed at which the heat is propagated in the material and thus increased specific heat to reach a value of $1380 \mathrm{~J} / \mathrm{kg} . \mathrm{K}$ for a percentage of $30 \%$. This can affect the thermal performance of SCCR which were significantly improved by the incorporation of rubber aggregates.

\section{Nomenclature}

$\mathrm{T}_{1} \quad$ Temperature of upper face of sample $\quad{ }^{\circ} \mathrm{C}$

$\mathrm{T}_{2} \quad$ Temperature of down face of sample $\quad{ }^{\circ} \mathrm{C}$

$\mathrm{T}_{\mathrm{a}} \quad$ Ambient temperature $\quad{ }^{\circ} \mathrm{C}$

$\mathrm{T}_{\mathrm{B}} \quad$ Temperature of the box $\quad{ }^{\circ} \mathrm{C}$

S Surface of sample $\quad \mathrm{m}^{2}$

E Thickness of sample m 


$\begin{array}{lll}\mathrm{R} & \text { Heater } & \\ \mathrm{C} & \text { Over all heat transfer coefficient } & \mathrm{W} / \mathrm{m}^{2} \mathrm{~K} \\ \mathrm{U} & \text { Potential difference } & \mathrm{V} \\ \mathrm{C}_{\mathrm{p}} & \text { Specific heat } & \mathrm{J} / \mathrm{Kg} \cdot \mathrm{K} \\ \mathrm{A} & \text { Thermal diffusivity } & \mathrm{m}^{2} / \mathrm{s} \\ \Lambda & \text { Thermal conductivity } & \mathrm{W} / \mathrm{mK} \\ \rho & \text { Density } & \mathrm{Kg} / \mathrm{m}^{3} \\ & \text { Heat flux } & \mathrm{W}\end{array}$

\section{Acknowledgments}

The authors wish to thank the civil engineering department of the higher institute of the technological studies of Sfax for their assistance in the experimental tests.

\section{References}

[1] Abdul H.A., "Mechanical and thermal properties of solid waste-based clay composites utilised and insulating materials," Int.J. of Thermal \& Environmental Engineering, Vol.6 (2), pp.89-94, 2013.

[2] ANPE, www.ANPE.tn.com.

[3] Toutanji H. A., "The use of rubber tire particles in concrete to replace mineral aggregates," Cement and Concrete Composites, Vol.18, pp. 135-139. 1995.

[4] Najim K. B. and Hall M. R., "A review of the fresh/hardened properties and applications for plain(PRC) and self-compacting rubberised concrete (SCRC)," Construction and Building Materials, Vol. 24, pp.2041-2051, 2010.

[5] Bignozzi M. C. and Sandrolini F., "Tyre rubber waste recycling in self-compacting concrete," Cement and Concrete Research, Vol. 24, pp.735-739, 2006.

[6] Eldin NN. and Senouci AB. Rubber-tire practices as concrete aggregate. J Civil Eng Mater;5(4):478-96,1993.

[7] Ei-dieb AS., Abdelw MM. and Abdel-hameed ME., "Concrete using tyre particles as aggregate" In: Proceedings of the international symposium, concrete technology unit. ISBN: 072772995 0: Thomas Telford Publishing;. p. 251-9, 2001.

[8] El-Gammal A., Abdel-Gawad AK., El-Sherbini Y. and Shalaby R.A., "Compressive strength of concrete utilizing waste tire rubber," J Emerg Trends Eng Appl Sci;1(1):96-9, 2010.

[9] Zheng LE., "Experimental investigation on dynamic properties of rubberized concrete," Constr Build Mater;22:939-47, 2008.

[10] Bonnet S., Turatsinze A. and Granju J.L., "Un composite cimentaire résistant à la fissuration: synergie granulats en caoutchou-renfort par fibresTyre," Bulletin des laboratoires des ponts et chaussées, 250-251 ref 4504, pp.43-54, (2004).

[11] Reda Taha MM., El-Ei-Dieb AS., Abd El-Wahab MA., and Abdel-Hameed ME., "Mechanical, fracture, and microstructural investigations of rubber concrete," $J$ Mater Civil Eng;20:640-9, 2008.

[12] Uygunoglu T. and Topçu IB., "The role of scrap rubber particles on the drying shrinkage and mechanical properties of self-consolidating mortars," Constr Build Mater;24(7):1141-50, 2010.

[13] Bignozzi MC. and Sandrolini F., "Tyre rubber waste recycling in self-compacting concrete," Cem Concr Res;36(4):735-9, 2006

[14] Nanthagopalan P. and Sathanam M., "Fresh and hardened properties of selfcompacting concrete produced with manufactured sand," Cem Concr Compos2010;33(3):353-8.

[15] NF EN 934-2+A1, "Admixtures for concrete.mortar and grout-Part 2: concrete admixtures-Definitions, requirements, conformity, marking and labelling," (2012).

[16] Okamura H. and Ozawa K., "Mix-design for selfcompacting concrete," Concrete Library of JSCE,25, pp.107-120, 1995

[17] EFNARC. The european guidlines for self-compacting concrete - specification,production and use; 2005.

[18] NF EN ISO 8990, "Thermal insulation-Determination of steady-state thermal transmission properties-Calibrated and guarded hot box," (1996).

[19] El Bakkouri, A., "Caractérisation hygroscopique, thermophysique et mécanique des matériaux allégés : le platre, le liège, la brique creuse," Thèse de Doctorat en science, Tétouan, Maroc, 2004.

[20] El Bouardi, A., "Etude en régime stationnaire et dynamique des propriétés thermophysiques de matériaux poreux humides non saturés utilisés en Génie Civil," Thèse de Doctorat d'Etat, Rabat, 1991.

[21] Degiovanni, A., "Thermal conduction in multilayer slab with internal sources using a quadripolar method," Int. J. Heat and Mass Transfer, Vol.31, ํ3, pp. 553-557, 1988.

[22] Taoukil, D., El Bouardi, A., Ajzoul, T. and Ezbakhe, H., "Effect of the incorporation of wood wool on the thermal physical properties of sand mortars", KSCE Journal of Civil Engineering, 16(6), pp.1003-1010, 2012.

[23] NF EN ISO 7345,'”Thermal insulation-Physical quantities and definitions," (1996)

[24] Topcu, U.B., "The properties of rubberized concrete," Cement and Concrete Research, Vol.25, N², pp. 304310,1995 . 